\title{
Bupivacaine-Sufentanil Versus Bupivacaine-Fentanyl in Spinal Anesthesia of Patients Undergoing Lower Extremity Surgery
}

\author{
Valiollah Hassani ${ }^{1,2}$; Gholamreza Movassaghi ${ }^{2}$; Reza Safaian ${ }^{2}$; Saeid Safari ${ }^{2}$; Mohammad \\ Mahdi Zamani ${ }^{2}$; Maryam Hajiashrafi, ${ }^{2,} ;$ Minow Sedaghat ${ }^{2}$ \\ ${ }_{1}^{1}$ Minimally Invasive Surgery Research Center, Iran University of Medical Sciences, Tehran, Iran \\ ${ }^{2}$ Department of Anesthesiology, Rasoul Akram Medical Center, Iran University of Medical Sciences, Tehran, Iran \\ ${ }^{*}$ Corresponding author: Maryam Hajiashrafi, Department of Anesthesiology and Pain Medicine, Rasoul Akram Medical Center, Iran University of Medical Sciences, Tehran, Iran. Tel/ \\ Fax: +98-2166509059, E-mail: maryam_hajiashrafi@yahoo.com \\ Received: May 8, 2013; Revised: July 26, 2013; Accepted: August 28, 2013
}

\begin{abstract}
Background: The addition of intrathecal opioids to local anesthetics seems to improve the quality of analgesia and prolong the duration of analgesia, when using a subarachnoid block in Iranian patients with their specific pain tolerance.

Objectives: The aim of this study was to evaluate the effects of adding fentanyl or sufentanil, to intrathecal bupivacaine, in terms of the onset and duration of; sensory block, motor block, hemodynamic effects and postoperative pain relief.

Patients and Methods: This randomized clinical trial included 90 patients who underwent orthopedic lower limb surgeries. Subjects were divided into experimental groups; intrathecal fentanyl $25 \mu \mathrm{g}(\mathrm{F})$, and sufentanil $2.5 \mu \mathrm{g}(\mathrm{S})$, along with a placebo $0.5 \mathrm{~mL}$ normal saline (C) group, which were added to bupivacaine $0.5 \%, 15 \mathrm{mg}$. Duration of complete and effective analgesia was recorded (by a visual analogue scale-VAS). The pain scores were assessed postoperatively. Intraoperative mean arterial pressure (MAP), heart rate and oxygen saturation $\left(\mathrm{SPO}^{2}\right)$ were recorded. The incidence of side effects such as; nausea, vomiting, pruritus, shivering, bradycardia and hypotension were also recorded.

Results: MAP and heart rate results showed no significant changes at the designated time points among the three groups $(\mathrm{P}>0.05)$. However, $\mathrm{SPO}_{2}$ and VAS showed significant changes at the designated time points among the three groups $(\mathrm{P}<0.05)$. The duration of complete and effective analgesia was also significantly longer in the sufentanil group $(\mathrm{P}<0.05)$. Motor block did not exhibit any significant difference $(\mathrm{P}=0.67)$. Only pruritus as a side effect was significantly higher in the sufentanil group $(\mathrm{P}<0.05)$, while all other evaluated side effects were significantly lower in the sufentanil group $(\mathrm{P}<0.05)$.

Conclusions: The addition of $2.5-3 \mathrm{mcg}$ sufentanil to $15 \mathrm{mg}$ 0.05\% bupivacaine maintained the patient's hemodynamic stability similar to fentanyl. Intrathecal sufentanil added to bupivacaine,when compared with fentanyl, may lead to prolonged duration of analgesia, facilitate the spread of the sensory block, increase mean SPO2 levels, and reduce overall side effects.
\end{abstract}

Keywords: Analgesia; Anesthesia, Spinal; Bupivacaine; Fentanyl; Sufentanil

\section{Background}

Spinal anesthesia (SA) is widely used in abdominal and lower extremity's surgeries due to its safety and simplicity, as well as the shorter time period that it needs to be completed $(1,2)$. Regarding high morbidity and increased risk of postoperative bleeding and nausea during the postoperative period in general anesthesia, SA seems to be a better method. Nowadays, the most common drug used for SA is bupivacaine (3). However, in addition to its inclusive effects, SA can result in urinary retention and prolong a patients' stay in the hospital. Furthermore, due to its short duration of action, bupivacaine needs other adjuvant drugs to increase its duration of action, such as opioids $(4,5)$. These drugs have a synergistic effect with bupivacaine and they can improve the anesthesia and prolong its activity (6). Using opioids results in a high incidence of nausea, urinary retention and respiratory depression (7). Fentanyl and sufentanil, which are lipophilic opioid drugs, have replaced other kinds of opioids, as they are highly soluble in lipids and potent blocking opium receptors, with fewer side effects (8). A metaanalysis, which investigated 28 randomized trials in 2013, indicated that the effects of intrathecal local anesthetics were only comparable with a reduced dose of the same local anesthetics when used with a concomitant opioid. In this meta-analysis, 19 trials used bupivacaine as local anesthetics, and 23 trials used fentanyl as a concomitant

Implication for health policy/practice/research/medical education:

Based on the results of this study, adding sufentanil to intrathecal bupivacaine can increase a patient's hemodynamic measurements, in addition to maximizing sensation block and anesthesia duration.

Copyright (C) 2014, Iranian Society of Regional Anesthesia and Pain Medicine(ISRAPM); Published by KowsarCorp. This is an open-access article distributed under the terms of the Creative Commons Attribution License, which permits unrestricted use, distribution, and reproduction in any medium, provided the original work is properly cited. 
opioid. Sufentanil has been investigated in several studies and there was a greater requirement to clear its effects with intratechal anesthetic agents (9). In another metaanalysis of 65 trials conducted by Popping et al. and published between 1983 and 2010, included 3338 patients, of whom 1932 received opioids, it was found that morphine (0.05-2 mg) and fentanyl (10-50 $\mu \mathrm{g}$ ) added to bupivacaine were the most frequently tested opioids and the authors demonstrated that there were not enough studies to allow for significant conclusions on the concomitant intratechal opioids; intrathecal buprenorphine, diamorphine, hydromorphone, meperidine, methadone, pentazocine, sufentanil, and tramadol (10). On the other hand, sufentanil reduces the bupivacaine dose required for desired anesthesia, and results in better cardiac output during surgery. The increasing demand for SA in orthopedic surgeries and the importance of the pharmacokinetic and pharmacology of new drugs made us appreciate the importance of studying the effects of new adjuvant drugs in SA $(11,12)$. Moreover, there are no studies about the specific aspects of this technique on different cultures with different pain experience; Dawson et al. demonstrated that middle eastern people are different in pain tolerance compared with European ones (13).

\section{Objectives}

We aimed to evaluate the improved effects of intrathecal sufentanil or fentanyl along with bupivacaine, during and after lower extremities orthopedic surgery.

\section{Patients and Methods}

This double-blind randomized clinical trial was conducted on elective patients who had orthopedic surgery on their lower extremities, and who were referred to the Rasoul-e-Akram and Firoozgar Hospitals, in 2012. Before any intervention, all potential candidates were informed about the study before they decided whether to participate or not, and a written consent was obtained. The patients were not charged any additional fees for the drugs at any stage of this study. All information was kept confidential and all authors were bound by the Helsinki declaration (IRCT: $201209045822 \mathrm{~N} 2$ ).

Subjects who had indications for elective orthopedic surgery on their lower extremities and American Society of Anesthesiologists (ASA) level I or II, were entered into this study. Exclusion criteria were, history of discomfort from a previous SA, disability in the sitting position, coagulation disorders, non-compensated liver failure, severe renal failure $(\mathrm{GFR}<60)$, heart failure $(\mathrm{EF}<5 \%)$, any kind of heart block age, heart arrhythmia, confirmed hypertension, diabetes, obesity (BMI > 30), neurologic disorders, psychiatric disorders, history of spinal surgery, or any hypersensitivity to opioid or anesthesia drugs, pregnancy, alcohol or substance abuse. All patients who had any requirements for anesthesia higher than T4 or lower than
T10 levels were also excluded. Subjects were randomly assigned to three equal groups; fentanyl, sufentanil or placebo group. Routine monitoring of electrocardiogram (ECG), pulse oximetry, and non-invasive blood pressure (NIBP), was conducted prior to the SA. All patients were routed with a green (18 gauge) catheter and infused with 3-4 cc/kg isotonic crystalloids. Subjects underwent intrathecal injection of $15 \mathrm{mg}$ isobar bupivacaine, and one of the three following additives: 0.5-0.6 mL normal saline; 25-30 mcg fentanyl or 2.5-3 mcg sufentanil. The syringes were filled with one of the above drugs by an anesthesiology technician and handed to the blinded anesthesiologist for injection. The intrathecal injection was carried out in the sitting position for all three groups. The checklists were filled by the same blinded anesthesiologist. Position of the patient was supine for all subjects, during the operation. The pneumatic cuff tourniquet was used for all patients with a cuff pressure of $300 \mathrm{mmHg}$, for the duration the surgery.

The patients received the spinal anesthetic through a 25-gauge Crawford needle. In the median approach the dural puncture was performed in the L3-4, or L4-5 interspaces, with the patients in the sitting position by an anesthesiologist, blinded to the syringes content. The anesthesia field was evaluated by a cotton peak (for heat perception), or a needle (for touching sense), every 15-20 seconds, then the motor block was evaluated using the Bromage scale as following: $0=$ no paralysis; $1=$ inability to raise extended leg; 2 = inability to flex knee; $3=$ inability to move leg joints. Pulse rate, blood pressure and arterial blood oxygen saturation were evaluated every 2 minutes in the first 20 minutes, and every 5 minutes till the patient was transferred to the recovery room. The patient was excluded if any additional sedative or narcotic was used. The anesthesia start was calculated from the end of the injection and the anesthesia period was calculated from the start of the anesthesia till the first pain response of the patient after the end of surgery. The patient was asked about nausea, vomiting, pruritus and drowsiness. The patients were treated with $0.1 \mathrm{mg} / \mathrm{kg}$ metoclopramide if required. The patients' pain levels were evaluated in the 1st, 2nd, 6th, 12th, 18th and 24th hour after recovery by a visual analogue scale (VAS). Intravenous $0.5 \mathrm{mg} / \mathrm{kg}$ meperidine was administrated and repeated if the pain was not tolerated (VAS $>3$ ). The time and dose were recorded. Any systolic blood pressure drop more than $20 \%$ or under $100 \mathrm{mmHg}$, and pulse rate drop to less than $60 / \mathrm{min}$, were recorded during the surgery. Other demographic information, such as, sex, age, weight, height, physical examination, and medical history were obtained from the patients' medical files.

The data were evaluated and analyzed by SPSS (version 19) (SPSS Inc., Illinois, USA). All quantitative data were expressed as mean \pm SD and qualitative data as No. (\%). Repeated measurements analysis and post-hoc tests were used for comparison of SBP, DBP, PR and $\mathrm{SPO}_{2}$ during the 
surgery. P value less than 0.05 were considered significant.

\section{Results}

\subsection{Demographic Data}

Ninety patients were conveniently enrolled and divided into three equal groups. The mean age of the patients was $32 \pm 15$ years, and consisted of 23 females and 68 males $(\mathrm{P}=0.35$ and $\mathrm{P}=0.66$, respectively). Other demographic data are demonstrated in Table 1. None of the subjects required a general anesthesia during surgery due to pain intolerance and no one was excluded because of a high spinal block.

\subsection{End Point Results}

\subsubsection{Maximum Sensational Block}

The sensory block of the sufentanil group was more common at T4 and T5 levels, but sensory block of the fentanyl group was more common at the T8 level $(\mathrm{P}<$ 0.05). The maximum sensation level of block in all three groups is demonstrated in Figure 1. Significant differences were seen among the three groups $(\mathrm{P}<0.05)$. The motor block did not exhibit any significant difference (P $=0.67)$.

\subsubsection{Vital Signs Changes}

Hypotension, bradycardia, nausea, vomiting, metochloropramide requirement, pruritus, shivering and drowsiness were evaluated in all 3 groups and demonstrated in Table 1. As seen, both of nausea and vomiting were significantly lower in sufentanil group compare with fentanyl group $(\mathrm{P}<0.05)$. Metoclopramide was administrated for 5 patients (1 subject in placebo group and 1 subject in fentanyl group)

Sufentanil had more stable blood pressures (the lowest changes) comparing with other groups $(\mathrm{P}<0.05)$ (Figure $2 \mathrm{~A}, \mathrm{~B}$ ). The HR changes did not have any significant difference among three groups $(\mathrm{P}=0.99)$ which was $77 \pm 13$ per min, $78 \pm 14$ per min and $76 \pm 11$ in sufentanil, fentanyl and placebo groups respectively. However, $\mathrm{SPO}_{2}$ showed significant difference in Figure $2 \mathrm{C}$ at 2ed, 4th, 6th, 10th and 12th minutes of evaluation, showing more stable $\mathrm{SPO}_{2}$ in sufentanil $(\mathrm{P}<0.05)$.

\subsubsection{Pain Evaluation}

Figure 3 presents the pain score which was in the lowest level for sufentanil group, and in the highest one in placebo group. The properties of intraoperative and postoperative analgesia are shown in Table 2. All VAS changes among three groups are significant $(\mathrm{P}<0.05)$. True anesthesia time, effective Anastasia time and immobilization time were the highest in sufentanil group and additional opioid injection dose and time was the lowest in sufentanil group also.

\subsubsection{Side Effects}

Hypotension was significantly lower, and pruritus had a higher prevalence rate in the sufentanil group $(\mathrm{P}<$ 0.05). Other side effects (bradycardia, nausea, vomiting and drowsiness) did not differ significantly (Table 1).

Table 1. Demographic Data and Adverse Effects of Three Groups of the Study ${ }^{\text {a }}$

\begin{tabular}{|c|c|c|c|c|}
\hline & Sufentanil & Fentanyl & Placebo & P Value \\
\hline Age, y & $35 \pm 7$ & $36 \pm 11$ & $41 \pm 11$ & 0.35 \\
\hline BMI, $\mathrm{kg} / \mathrm{m}^{2}$ & $25 \pm 1$ & $25 \pm 2$ & $26 \pm 2$ & 0.59 \\
\hline $\begin{array}{l}\text { Surgery Duration, } \\
\text { min }\end{array}$ & $154 \pm 15$ & $132 \pm 41$ & $98 \pm 8$ & 0.11 \\
\hline Sex & 24 & 21 & 22 & \\
\hline \multicolumn{5}{|l|}{ Male } \\
\hline Female & 6 & 9 & 8 & 0.66 \\
\hline ASA class & 22 & 19 & 25 & \\
\hline \multicolumn{5}{|l|}{ I } \\
\hline II & 8 & 11 & 5 & 0.21 \\
\hline \multicolumn{5}{|l|}{$\begin{array}{l}\text { Adverse Effects, } \\
\text { No. }\end{array}$} \\
\hline Hypotension & 5 & 8 & 6 & 0.62 \\
\hline Bradycardia & 0 & 0 & 2 & 0.12 \\
\hline Nausea & 0 & 4 & 1 & $0.01^{b}$ \\
\hline Vomiting & 0 & 3 & 0 & $00.04^{b}$ \\
\hline $\begin{array}{l}\text { Antiemetic Drug } \\
\text { use }\end{array}$ & 0 & 1 & 1 & 0.36 \\
\hline Pruritus & 6 & 2 & 0 & $0.01^{b}$ \\
\hline
\end{tabular}

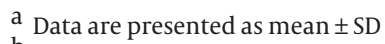

b P value $<0.05$

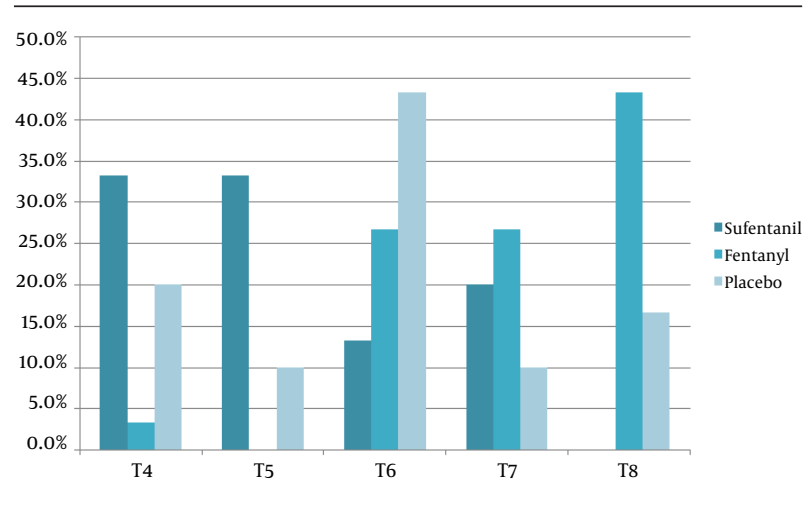

Figure 1. Percentage of Patients With Different Levels of Sensational Block (T4 to T8), in the Three Groups 
Hassani Vet al.

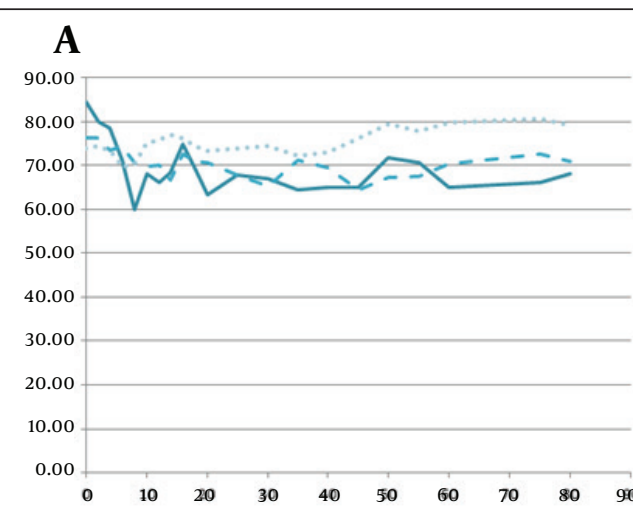

\section{Discussion}

Subarachnoid block or spinal anesthesia (SA) is a common method for abdominal and lower extremities' anesthesia. Many studies have demonstrated that SA can reduce venous thromboembolism in lower extremities' orthopedic surgeries and induce short term and rapid onset anesthesia $(8,14)$. Other adjuvant drugs can improve the anesthetic effects, such as opioids (15). Duration of anesthesia is prolonged by using opioids such as morphine; however, they may result in respiratory depression. Therefore, lipophilic opioids like fentanyl and sufentanil have been suggested (16).

Our study demonstrated significant changes in SPO2 and hemodynamic levels, among our three groups, and sufentanil had more stable vital signs than fentanyl or a placebo $(\mathrm{P}<0.05)$, except for $\mathrm{PR}$ changes $(\mathrm{P}=0.99)$. Blockage of preganglionic afferent sympathetic nerves at the level of T1-T4, results in a drop in blood pressure and a decrease in pulse rate, which can cause negative inotropic and chronotropic effects $(17,18)$. The $\mathrm{SPO}_{2}$ changes showed greater fluctuation than the other parameters, however, the sufentanil group had more stable $\mathrm{SPO}_{2}$ and none of the patients had a recorded $\mathrm{SPO}_{2}$ level of less than $96 \%$, which were in accord with other studies results. Regarding assurance of results in the literature, respiratory depression is still one of the most annoying issues for anesthesiologists using lipophilic opioids. There is evidence which shows these drugs can also induce respiratory depression $(19,20)$.

Our study demonstrated no significant difference between the maximum levels of sensation block, which were at T4-T5 in the sufentanil group. Other studies had shown a level of T6 in both fentanyl and sufentanil (17, 21). Furthermore, sensed pain was significantly lower, and true and effective anesthesia were significantly higher in the sufentanil group, which supports the results of other studies (17). The $\mu$ agonists of both fentan$\mathrm{yl}$ and sufentanil induce lower voltage at the $\mathrm{Ca}^{2+}$ gates and open the $\mathrm{K}^{+}$gates, which can drive the nerve into a post-synaptic hyper-polarization and result in reduced nerve conduction. Bupivacaine can inhibit the $\mathrm{Na}^{+}$gates and help both fentanyl and sufentanil in anesthesia. Other studies have reported a 0 to $100 \%$ incidence of pruritus using lipophilic opioids, and we found that pruritus occurred in $20 \%$ of patients in sufentanil group, but this was the only side effects which had a higher prevalence among the three group. In other studies, nausea and vomiting had a dose dependent incidence of nearly $30 \%$, although this study presented with a $0 \%$ incidence of nausea and vomiting using $2.5-3$ mcg intrathecal sufentanil. However, these studies have also stated that the side effects may differ from hospital to hospital based on other factors, such as room temperature and the type of crystalloid used (22-24).

Figure 3. Visual Analogue Scale (VAS) of Postoperative Pain Change (hour) in the Three Groups 
Hassani Vet al.

\begin{tabular}{|c|c|c|c|c|c|c|}
\hline Time & Sufentanil & Fentanyl & Placebo & $\mathbf{p}^{1}$ & $\mathbf{p}^{2}$ & $\mathbf{p}^{3}$ \\
\hline Analgesia time, min & $171 \pm 19$ & $168 \pm 28$ & $122 \pm 20$ & 0.0001 & 0.0001 & $0.542^{b}$ \\
\hline Effective analgesia time, min & $214 \pm 22$ & $163 \pm 21$ & $146 \pm 14$ & 0.0001 & 0.012 & 0.0001 \\
\hline Immobilization time, min & $226 \pm 27$ & $209 \pm 14$ & $159 \pm 17$ & 0.0001 & 0.0001 & 0.009 \\
\hline First opioid request, hr & $4.9 \pm 1.3$ & $4.2 \pm 2$ & $3.8 \pm 1.1$ & 0.0001 & $0.156^{\mathrm{b}}$ & $0.057^{b}$ \\
\hline Dose of opioid, mg & $1 \pm 0.6$ & $1.1 \pm 0.3$ & $2 \pm 0.6$ & 0.0001 & 0.024 & $0.75^{b}$ \\
\hline \multicolumn{7}{|l|}{ Pain Score, VAS } \\
\hline 1st hour & $1.6 \pm 0.7$ & $3 \pm 1.2$ & $3.3 \pm 1$ & 0.0001 & $0.341^{b}$ & 0.0001 \\
\hline 2nd hour & $3.9 \pm 1.8$ & $4.6 \pm 1.6$ & $5.7 \pm 1.7$ & 0.0001 & 0.0001 & 0.0001 \\
\hline 6th Hour & $4.5 \pm 2$ & $5.4 \pm 1.8$ & $6.9 \pm 2.7$ & 0.0001 & 0.0001 & 0.004 \\
\hline 12th hour & $5.4 \pm 2$ & $5.5 \pm 2.1$ & $7.7 \pm 3$ & 0.0001 & 0.0001 & 0.033 \\
\hline 18th hour & $5.2 \pm 1.8$ & $5.9 \pm 1.6$ & $7.8 \pm 1.9$ & 0.0001 & 0.0001 & 0.0001 \\
\hline 24th hour & $5.7 \pm 1.2$ & $6.3 \pm 1.9$ & $7.3 \pm 2$ & 0.0001 & 0.003 & 0.012 \\
\hline
\end{tabular}

a data are presented as Mean \pm SD.

b VAS, Visual Analogue Scale; $\mathrm{p}^{1}$, Sufentanil vs. Placebo; $\mathrm{p}^{2}$, Fentanyl vs. Placebo; $\mathrm{p}^{3}$, Sufentanil vs. Fentanyl.

c P value $>0.05$

In summary, the addition of 2.5-3 mcg sufentanil to 15 mg 0.05\% bupivacaine maintains patient's hemodynamic stability, along with maximum sensation block and anesthesia duration. In addition, it can reduce the incidence of hypotension compared with fentanyl. Pruritus is more common with sufentanil than with intratechal fentanyl. Finally, sufentanil compared with other regular and lipophilic opioids is recommended for SA as an adjuant intratechal drug along with isobar bupivacaine.

\section{Acknowledgements}

The authors are grateful to orthopedic surgeons Rasoule-Akram and Firoozgar Hospitals, for their cooperation.

\section{Authors' Contribution}

Conception and design, collection of data, critical revision of the article and administrative technical scientific revision of the article: Valiollah Hassani; conception and design, obtaining funding, data interpretation and writing the article: Gholamreza Movassaghi; conception and design, clinical analysis: Reza Safaian; literature search, clinical analysis and scientific revision of the article: Saeid Safari and Mohammad Mahdi Zamani; conception and design and assembly of data: Roya Nabizadeh and Minow Sedaghat; conception and design, data collection, critical revision of the article: Maryam Hajiashrafi.

\section{Financial Disclosure}

The authors have nothing to declare.

\section{Funding/Support}

The research presented in this manuscript has been funded by Iran University of Medical Sciences Thesis grants.

\section{References}

1. Mauermann WJ, Shilling AM, Zuo Z. A comparison of neuraxial block versus general anesthesia for elective total hip replacement: a meta-analysis. Anesth Analg. 2006;103(4):1018-25.

2. Valentin N, Lomholt B, Jensen JS, Hejgaard N, Kreiner S. Spinal or general anaesthesia for surgery of the fractured hip? A prospective study of mortality in 578 patients. Br J Anaesth. 1986;58(3):284-91.

3. Cousins MJ, Mather LE. Intrathecal and epidural administration of opioids. Anesthesiology.1984;61(3):276-310.

4. Abouleish E, Rawal N, Shaw J, Lorenz T, Rashad MN. Intrathecal morphine $0.2 \mathrm{mg}$ versus epidural bupivacaine $0.125 \%$ or their combination: effects on parturients. Anesthesiology. 1991;74(4):711-6.

5. Hunt CO, Naulty JS, Bader AM, Hauch MA, Vartikar JV, Datta S, et al. Perioperative analgesia with subarachnoid fentanyl-bupivacaine for cesarean delivery. Anesthesiology. 1989;71(4):535-40.

6. Etches RC, Sandler AN, Daley MD. Respiratory depression and spinal opioids. Can J Anaesth.1989;36(2):165-85.

7. Gustafsson LL, Wiesenfeld-Hallin Z. Spinal opioid analgesia. A critical update. Drugs. 1988;35(6):597-603.

8. Akerman B,Arwestrom E, Post C. Local anesthetics potentiate spinal morphine antinociception. Anesth Analg. 1988;67(10):943-8.

9. Popping DM, Elia N, Wenk M, Tramer MR. Combination of a reduced dose of an intrathecal local anesthetic with a small dose of an opioid: a meta-analysis of randomized trials. Pain. 2013;154(8):1383-90.

10. Popping DM, Elia N, Marret E, Wenk M, Tramer MR. Opioids added to local anesthetics for single-shot intrathecal anesthesia in patients undergoing minor surgery: a meta-analysis of randomized trials. Pain. 2012;153(4):784-93.

11. Asehnoune K, Larousse E, Tadie JM, Minville V, Droupy S, Benhamou D. Small-dose bupivacaine-sufentanil prevents cardiac output modifications after spinal anesthesia. Anesth Analg. 2005;101(5):1512-5.

12. Olofsson C, Nygards EB, Bjersten AB, Hessling A. Low-dose bupivacaine with sufentanil prevents hypotension after spinal anesthesia for hip repair in elderly patients. Acta Anaesthesiol Scand. 2004;48(10):1240-4.

13. Dawson A, List T. Comparison of pain thresholds and pain tolerance levels between Middle Easterners and Swedes and between genders. J Oral Rehabil. 2009;36(4):271-8.

14. Fraser HM, Chapman V, Dickenson AH. Spinal local anaesthetic actions on afferent evoked responses and wind-up of nociceptive neurones in the rat spinal cord: combination with morphine produces marked potentiation of antinociception. Pain. 


\section{Hassani Vet al.}

1992;49(1):33-41.

15. Golfam P, Yari M, Bakhtiyari HR. Minimum appropriate dose of lidocaine with a fixed dose of sufentanil epinephrine used for spinal anesthesia in caesarian section. Anesth Pain Med. 2013;2(3):123-6

16. Meininger D, Byhahn C, Kessler P, Nordmeyer J, Alparslan Y, Hall BA, et al. Intrathecal fentanyl, sufentanil, or placebo combined with hyperbaric mepivacaine $2 \%$ for parturients undergoing elective cesarean delivery. Anesth Analg. 2003;96(3):852-8.

17. Dahlgren G, Hultstrand C, Jakobsson J, Norman M, Eriksson EW Martin H. Intrathecal sufentanil, fentanyl, or placebo added to bupivacaine for cesarean section. Anesth Analg. 1997;85(6):1288-93.

18. Reuben SS, Dunn SM, Duprat KM, O'Sullivan P. An intrathecal fentanyl dose-response study in lower extremity revascularization procedures. Anesthesiology. 1994;81(6):1371-5.

19. Hansdottir V, Hedner T, Woestenborghs R, Nordberg G. The CSF and plasma pharmacokinetics of sufentanil after intrathecal administration. Anesthesiology. 1991;74(2):264-9.

20. Hays RL, Palmer CM. Respiratory depression after intrathecal sufentanil during labor. Anesthesiol. 1994;81(2):511-2.

21. Lu JK, Manullang TR, Staples MH, Kem SE, Balley PL. Maternal respiratory arrests, severe hypotension, and fetal distress after administration of intrathecal, sufentanil, and bupivacaine after intravenous fentanyl. Anesthesiology. 1997;87(1):170-2.

22. Bailey PL, Rhondeau S, Schafer PG, Lu JK, Timmins BS, Foster W, et al. Dose-response pharmacology of intrathecal morphine in human volunteers. Anesthesiology.1993;79(1):49-59.

23. Chaney MA. Side effects of intrathecal and epidural opioids. Can JAnaesth. 1995;42(10):891-903.

24. Techanivate A, Urusopone P, Kiatgungwanglia P, Kosawiboonpol R. Intrathecal fentanyl in spinal anesthesia for appendectomy. $J$ Med Assoc Thai. 2004;87(5):525-30. 